\title{
ОЦЕНКА ДЕФИЦИТА ТРУДОВЫХ РЕСУРСОВ В РОССИИ НА ФОНЕ ПАНДЕМИИ "
}

\author{
(c) 2020 Олейник Елена Борисовна \\ доктор экономических наук, доцент, профессор кафедры \\ Дальневосточный федеральный университет, Россия, Владивосток \\ E-mail: oleynik.eb@dvfu.ru
}

Рассмотрена динамика численности трудоспособного населения России и показатели внешней миграции. С помощью регрессионной модели оценен вклад дефицита трудовых ресурсов, возникший на фоне пандемии, в сокращение ВВП. Проанализирована динамика вакансий. Сделан вывод о сохранении дефицита рабочих рук на российском рынке труда.

Ключевые слова: трудоспособное население, трудовые мигранты, регрессионная модель, прирост валового внутреннего продукта, рынок труда, дефицит трудовых ресурсов

В России неуклонно сокращается численность трудоспособного населения (рис. 1). Общая убыль численности трудоспособного населения до 2030 года, по разным прогнозам, составит от 11 до 13 млн. человек [1], за период 2017-2019 гг. сокращение рабочей силы составило 1097 тыс. человек, что может создать огромные трудности на российском рынке труда. Из-за таких темпов убыли населения можно ожидать снижение места России в мировой демографической иерархии: к 2050 г., согласно прогнозу ООН, она будет занимать в списке крупнейших стран только 15-е место. Сокращение трудоспособного населения неизменно приводит к снижению темпов эконо- мического роста. «Экономический рост зависит от масштаба предложения труда, и в развитых странах мигранты могут составлять значительную часть совокупного предложения. Старение населения и сокращение доли молодых когорт в рабочей силе, рост уровня образования и структурные сдвиги в сторону сектора услуг ограничивают предложение труда. Миграция помогает смягчать возникающий дефицит рабочей силы в отдельных отраслях и на отдельных территориях» [4]. Эти закономерности определяют развитие миграционных процессов и в России.

В России прирост трудоспособного населения за последние 8 лет обеспечивается исключи-

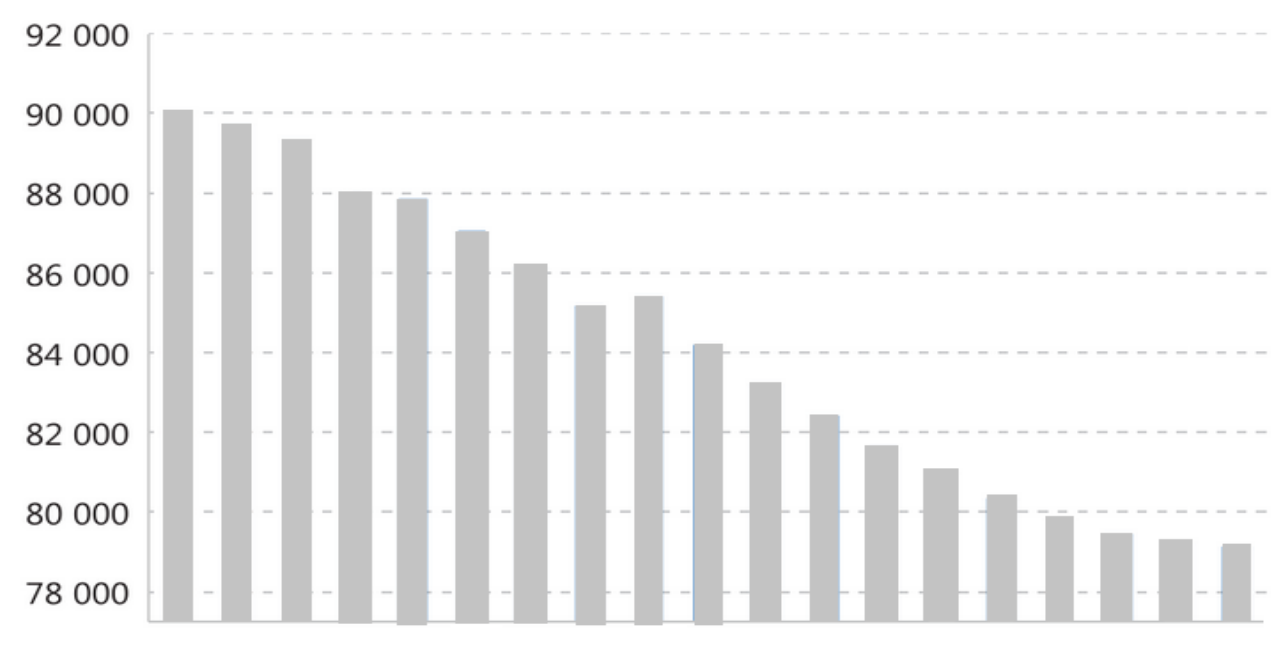

2007200820092010201120122013201420152016201720182019202020212022202320242025

Puc. 1. Численность трудоспособного населения в РФ, млн. человек Источник: данные [2, 10]

\footnotetext{
* Работа выполнена при поддержке Российского фонда фундаментальных исследований, грант № 19-01000206 «Моделирование миграционных потоков территорий и оценка результативности инструментов миграционной политики»
} 
тельно за счет миграции, а пандемия привела к возвращению части мигрантов на родину. Приток трудовых мигрантов из-за рубежа в Россию в январе-сентябре 2020 года сократился в 2,23 раза по сравнению с аналогичным периодом прошлого года (табл. 1).

Сокращение произошло по всем категориям иностранных работников. В частности, число мигрантов, работающих на основании патентов снизилось до 1,4 млн. против 1,7 млн. в сентябре 2019 года, а количество действительных разрешений на работу за год сократилось с 121,8 тыс. до 85,7 тысячи. Согласно исследованию Центра стратегических разработок, около $40 \%$ российских компаний, которые нанимали на работу трудовых мигрантов, во второй половине 2020 г. испытывают дефицит рабочей силы. При этом
19\% компаний упомянули меньший процент увольнений среди иностранцев. Наибольшее количество трудовых мигрантов по данным [8] приходится на Узбекистан и Таджикистан (рис. 2).

Тенденция к увеличению притока рабочей силы из стран ближнего зарубежья довольно четко прослеживалась до 2017 года, после чего несколько снизилась за счет жителей Украины и Молдавии, у которых открылся альтернативный рынок труда в Европе. Поток мигрантов из других государств не иссякал. К процессу активно подключился Китай, снабжая рабочей силой восточные регионы нашей страны.

В основном мигранты заняты в таких сферах деятельности, как строительство (около 40\%), торговля и ремонтные работы (19\%), промышленность (7\%), коммунальные и прочие услуги

Таблица 1. Показатели динамики внешней миграции, тыс. чел.

\begin{tabular}{|c|c|c|c|c|c|c|c|c|c|}
\hline \multirow{5}{*}{ Показатель } & \multirow{5}{*}{$\begin{array}{l}\text { Оформ- } \\
\text { лено } \\
\text { пригла- } \\
\text { шений }\end{array}$} & \multicolumn{8}{|c|}{ Миграционный учет } \\
\hline & & \multirow{4}{*}{$\begin{array}{c}\text { Количест } \\
\text { во фактов } \\
\text { постановки } \\
\text { на мигра- } \\
\text { ционный } \\
\text { учет }\end{array}$} & \multicolumn{7}{|c|}{ в том числе: } \\
\hline & & & \multirow{3}{*}{$\begin{array}{c}\text { по } \\
\text { месту } \\
\text { житель- } \\
\text { ства }\end{array}$} & \multirow{3}{*}{$\begin{array}{c}\text { по } \\
\text { месту } \\
\text { пребы- } \\
\text { вания }\end{array}$} & \multicolumn{5}{|c|}{ в том числе: } \\
\hline & & & & & \multirow{2}{*}{$\begin{array}{c}\text { Пер } \\
\text { вично }\end{array}$} & \multicolumn{4}{|c|}{ из них по целям въезда: } \\
\hline & & & & & & туризм & учеба & работа & иное \\
\hline янв - сент 2019 г & 392 & 14940 & 425 & 14516 & 10802 & 3434 & 479 & 4253 & 2637 \\
\hline янв - сент 2020 г & 98 & 7575 & 346 & 7229 & 3442 & 365 & 217 & 1904 & 956 \\
\hline $\begin{array}{l}\text { Уменьшилось, } \\
\text { чел. }\end{array}$ & 293 & 7366 & 79 & 7287 & 7360 & 3069 & 262 & 2348 & 1681 \\
\hline $\begin{array}{l}\text { Уменьшилось, } \\
\text { раз }\end{array}$ & 3.98 & 1.97 & 1.23 & 2.01 & 3.14 & 9.41 & 2.21 & 2.23 & 2.76 \\
\hline $\begin{array}{l}\text { Коэффициент } \\
\text { роста }\end{array}$ & 0.25 & 0.51 & 0.81 & 0.50 & 0.32 & 0.11 & 0.45 & 0.45 & 0.36 \\
\hline
\end{tabular}

Источник: [8], расчеты автора

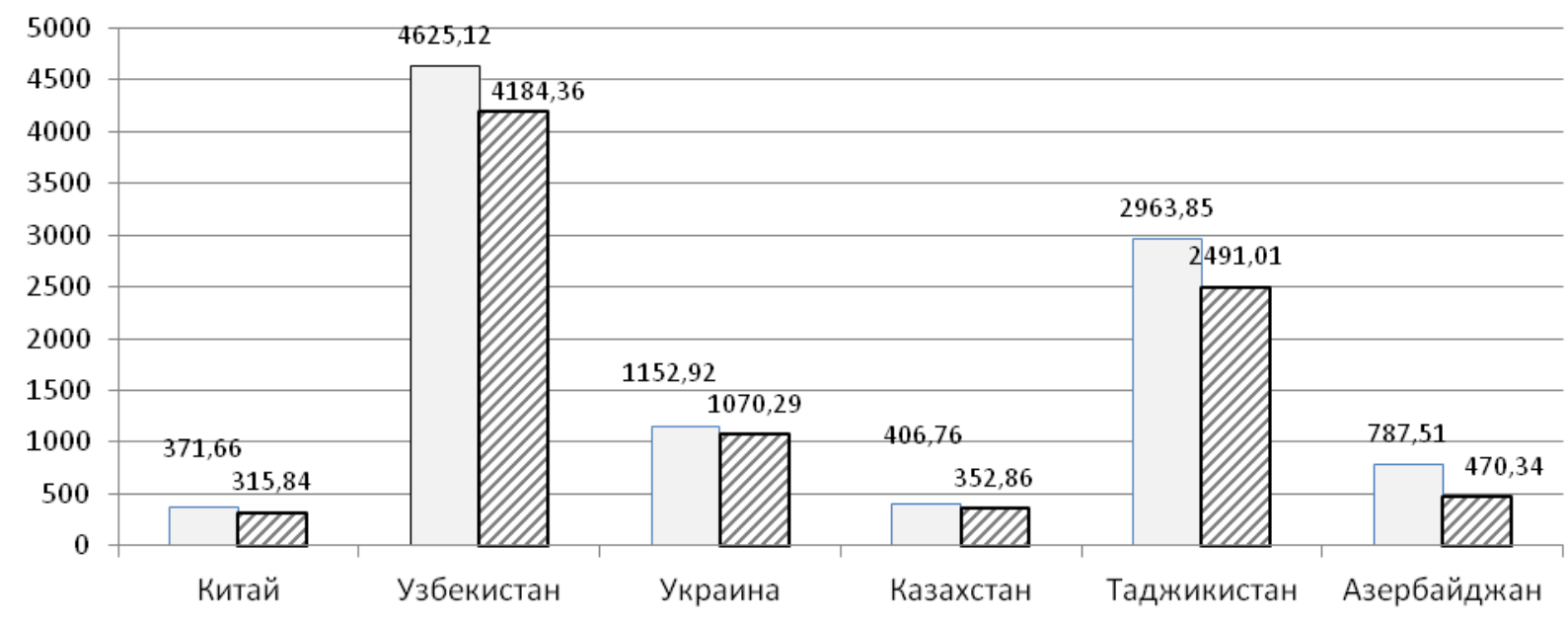

$\square$ За первые три квартала 2019 ■За первые три квартала 2020

Puc. 2. Основные потоки прибывших трудовых мигрантов 
(5\%), внутригородской транспорт и связь (4\%) [9]. Соответственно, в этих сферах экономики после закрытия границ был зафиксирован наибольший дефицит трудовых ресурсов. Многие работодатели, которые весной сокращали рабочий персонал из-за пандемии и остановки производств и сервисов, вынуждены нести дополнительные расходы на привлечение людей на опустевшем из-за снижения внешней и внутренней миграции рынке. Главное преимущество найма трудовых мигрантов для работодателей - их готовность работать за меньшие деньги по сравнению с россиянами.

По оценке Минэкономразвития России, в октябре падение валового внутреннего продукта (ВВП) в годовом выражении ускорилось до $-4,7 \%$ процентных пунктов (п/п) по сравнению с -3,0\% п/п в сентябре $(-3,6 \%$ п/п в 3 квартале 2020 , по данным [10]). Снижение ВВП по итогам 10 месяцев 2020 г. оценивается на уровне -3,6\% п/п. Основной вклад в усиление спада в октябре внесли обрабатывающая промышленность и сельское хозяйство. Оценим с помощью регрессионной модели дефицит трудовых ресурсов, возникший на фоне пандемии, который также вносит свой вклад в сокращение ВВП.

1. Сначала построим модель прироста ВВП. Источником исходных данных для моделирования является информация за период 3 квартал 2017 г.-3 квартал 2020 г. о трудовых мигрантах по данным МВД [8] и данным Федеральной службы государственной статистики о ВВП в ценах 2016 г. [10]. Результаты моделирования представлены на рис. 3, где $m$-Worker - число иностранных мигрантов.

Ind - бинарная переменная, которая принимает значения, равные 1 в первых кварталах, когда наблюдается снижение прироста ВВП вследствие, того, что в январе большинство мигрантов возвращается домой на январские каникулы. Эта переменная используется для того, чтобы выровнять сезонные колебания.

Уравнение регрессии в целом значимо по критерию Фишера, а коэффициенты регрессии значимы по критерию Стьюдента при уровне значимости $\alpha=0.05$, границы доверительного интервала имеют одинаковые знаки. Следовательно, уравнение регрессии (формула 1) может быть использовано для оценки $\triangle B B П$ - ежеквартального абсолютного прироста ВВП. Регрессия вида $\quad m_{W o r k e r}=f(\Delta$ ВВП, $I n d)$ оказалась незначимой, знаки и коэффициенты не интерпретируемы.

$$
\Delta \mathrm{BB \Pi}=43,3+0,001 * m_{\text {Worker }}-5335.91 * \text { Ind }+\varepsilon
$$

На рис 4 представлена фактическая и рассчитанная по уравнению (1) динамика поквартального изменения ВВП.

2. Среднее за квартал снижение ВВП в 2020 г. по сравнению с относительно благополучным 2019 г. составило 2464,8 млрд. руб. в ценах 2016 г.

3. Из формулы (1), выразив значение m_Worker, получим, что для того, чтобы только лишь вернуться к средним значениям ВВП за 2019 г. потребуется дополнительно привлечение 2412,7 тыс. трудовых мигрантов, то есть в полтора раза больше их максимального числа за период 2017-2019 гг.

К концу 2020 г. сложилась ситуация, когда наблюдается дефицит трудовых ресурсов в нишах, которые раньше занимали мигранты. Однако привлечь на эти вакансии местных жителей и приезжих из российских регионов может только заметное повышение предлагаемых зарплат. По данным Федеральной службы государственной статистики значительно сократилась миграция в пределах России: на 17,2\%, или на 449,2 тыс. человек, за январь - август 2020 года по сравнению с аналогичным периодом прошлого года.

\begin{tabular}{|c|c|c|c|c|c|c|}
\hline \multicolumn{7}{|c|}{ Дисперсионный анализ } \\
\hline & $d f$ & SS & MS & $F$ & Значимость $F$ & \\
\hline Регрессия & 2 & 68824038.31 & 34412019.16 & 91.98756747 & $3.01564 \mathrm{E}-06$ & \\
\hline Остаток & 8 & 2992753.921 & 374094.2402 & & & \\
\hline \multirow[t]{2}{*}{ Итого } & 10 & 71816792.23 & & & & \\
\hline & Коэффициенты & Стандартная ошибка & t-статистика & Р-значение & Нижние 95\% & Beрхние 95\% \\
\hline Y-пересечение & 43.2857 & 493.8132 & 0.0877 & 0.9323 & -1095.4497 & 1182.0211 \\
\hline m_Worker & 0.0010 & 0.0004 & 2.4930 & 0.0373 & 0.0001 & 0.0019 \\
\hline Ind & -5335.9163 & 420.6629 & -12.6845 & 0.0000 & -6305.9667 & -4365.8660 \\
\hline
\end{tabular}




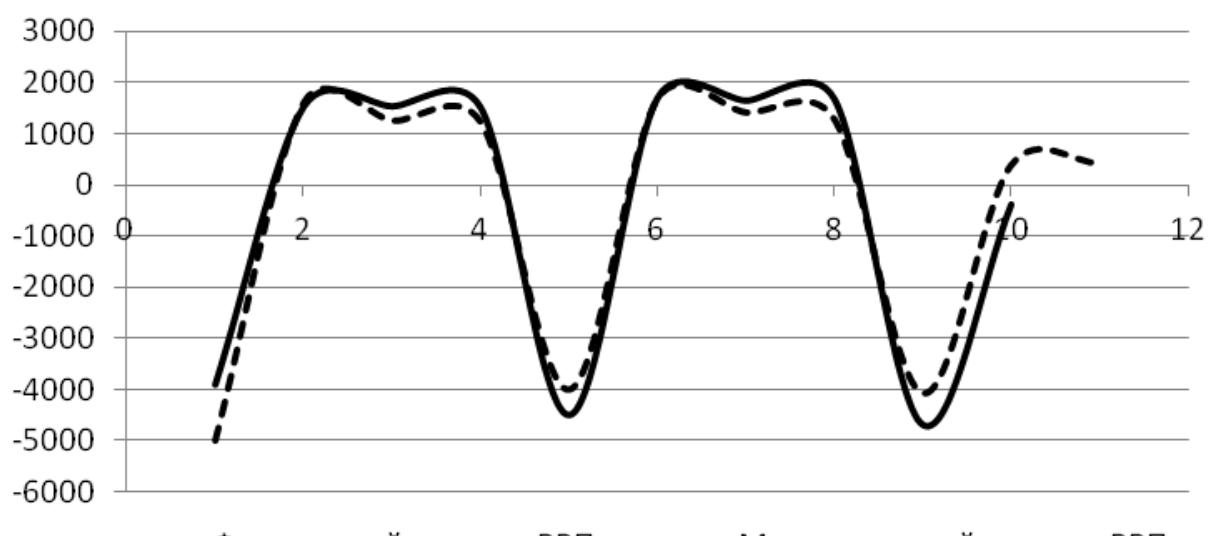

Puc. 4. Фактический и моделируемый поквартальный абсолютный прирост ВВП за 2017-2020 гг., млрд. руб.

Пандемия серьезно ударила по малообеспеченным слоям населения, а также частично по среднему классу. Росту численности малоимущего населения способствовало снижение деловой активности в период пандемии и, как следствие, снижение реальных денежных доходов. Число россиян с доходом ниже величины прожиточного минимума увеличилось во втором квартале 2020 года на 1,3 млн. по отношению к аналогичному периоду 2019 года и составило 19,9 млн. человек (13,5\% населения страны). По данным [10], во втором квартале 2019 года число бедных россиян составляло 18,6 млн. (12,7\% населения). Обострившаяся экономическая ситуация усилила характерное для нашего рынка труда явление - феномен «работающих бедных» [3]. С середины марта 2020 г. выявлена тенденция роста безработицы: к началу июня увольнения зафиксированы в каждой пятой компании и еще столько же отмечает, что риск сокращения сотрудников для них актуален и, вероятно, это произойдет в ближайший месяц. Уровень безработицы на основе экономических ожиданий в 2020 году может превысить 12\% (более 9 млн. человек), что почти в три раза выше, чем в докризисный период [5]. Ожидалось, что уход с рынка труда иностранных мигрантов и рост безработицы среди населения России должны были привести к замещению уехавших иностранных работников российскими гражданами, хотя бы в некоторых регионах и отраслях. Проанализируем динамику вакансий по видам деятельности (табл. 2). Наибольшее сокращение предложений наблюдается в сфере банковских услуг, туризма и сервиса. Наиболее востребованы специалисты медицины и фармацевтики, хотя у них предлагаемая заработная плата значительно ниже средней (47582 руб.), а также рабочие и строительные специалисты.

Дефицит кадров наблюдается среди специалистов добывающих отраслей, несмотря на то, что в этом виде деятельности предлагается са-

Таблица 2. Динамика вакансий на российском рынке труда по видам деятельности, январь-ноябрь 2020 г., процентные пункты

\begin{tabular}{|l|c|c|l|c|c|}
\hline \multicolumn{2}{|c|}{ Сократилось вакансий } & $\begin{array}{c}\text { Предлагаемая } \\
\text { 3/пл, руб. }\end{array}$ & \multicolumn{2}{|}{ Увеличилось вакансий } & $\begin{array}{c}\text { Предлагаемая } \\
\text { 3/пл, руб. }\end{array}$ \\
\hline Туризм, гостиницы, рестораны & 19 & 38488 & Рабочие специальности & 20 & 50208 \\
\hline Спортклубы, салоны красоты & 9 & 50347 & Строительные специальности & 19 & 61458 \\
\hline $\begin{array}{l}\text { Административно-управл. } \\
\text { персонал }\end{array}$ & 16 & 36928 & Производство & 3 & 48518 \\
\hline Сфера развлечений & 15 & 47457 & Медицина, фармацевтика & 39 & 44176 \\
\hline Маркетинг, реклама & 14 & 46531 & Наука, образование & 5 & 41403 \\
\hline Банковская сфера & 20 & 44178 & IТ-специалисты & 3 & 54901 \\
\hline Бухгалтерия, финанасы & 10 & 40439 & Обрабатывающие производства & 3 & 48518 \\
\hline Страхование & 14 & 45168 & Добыча сырья & 5 & 68262 \\
\hline
\end{tabular}

Источник: [6] 
Таблица 3. Динамика вакансий на российском рынке труда регионам, январь-ноябрь 2020 г.

\begin{tabular}{|l|c|c|}
\hline \multicolumn{1}{|c|}{ Территория } & Изменение числа вакансий & Предлагаемая з/пл, руб. \\
\hline Центральный федеральный округ & -1 & 43262 \\
\hline Северо-Западный федеральный округ & 0 & 43263 \\
\hline Южный федеральный округ & -1 & 40717 \\
\hline Северо-Кавказский федеральный округ & 2 & 39856 \\
\hline Приволжский федеральный округ & 8 & 44464 \\
\hline Уральский федеральный округ & 10 & 42161 \\
\hline Сибирский федеральный округ & 10 & 52923 \\
\hline Дальневосточный федеральный округ & 15 & 46716 \\
\hline Всего по России & 3 & 62675 \\
\hline Для сравнения: & -10 & 5111 \\
Москва & -11 & \\
Санкт-Петербург & & \\
\hline
\end{tabular}

Источник: [6]

мая высокая заработная плата -68262 руб. В таблице 3 представлена динамика изменения вакансий по регионам. Наибольший дефицит кадров и наибольшая предлагаемая заработная плата наблюдается в Дальневосточном федеральном округе. Возникла двойственная ситуация: значительный дефицит кадров сопровождается ростом безработицы среди россиян. «Безработные россияне - популяция с другими социальными, демографическими и профессиональными характеристиками. Даже если зарплата их соблазнит, им могут не подойти другие условия - переработки, низкие социальные гарантии, бытовые неудобства, на которые обычно соглашаются мигранты» [7].

Вследствие закрытия границ стало сложно оперативно привлекать временных работников в те отрасли, где возникала такая необходимость. Иностранные мигранты получили больше возможностей для выборов места работы. В то же время, в России, несмотря на рост безработицы, увеличивается дефицит трудовых ресурсов не только в строительстве, сфере услуг и сельском хозяйстве - нишах, традиционно привлекающих иностранных трудовых мигрантов. Наблюдается дефицит кадров в сфере информационных технологий, фарминдустрии и логистике.

Бизнес привык экономить на труде мигрантов. Дефицит работников привел к росту цен на жилье, а также к росту стоимости сельхозпродукции и услуг для потребителей. Конечно, рынок постепенно определит новую стоимость труда. Может произойти некоторое замедление скорости роста экономики, так как рост опирается на дешевую рабочую силу.

Очевидно, что дефицит иностранных рабочих рук на российском рынке труда в ближайшее время сохраниться. Уровень жизни, экономические и социальные возможности пребывания в России по-прежнему остаются привлекательными для жителей стран ближнего зарубежья.

\section{Библиографический список}

1. Андреев E., Вишневский А. Ближайшие демографические перспективы России / Демоскоп Weekly. 2014.№ 601.-602.- http://demoscope.ru/weekly/2014/0601/tema03.php (дата обращения: 21.11.2020)

2. Деминцева Е.Б.,. Мкртчян Н.В., Флоринская Ю.Ф. Миграционная политика: диагностика, вызовы, предложения.- М.: Центр стратегических разработок, 2018.-https://publications.hse.ru/mirror/pubs/share/direct/ 217173907.pdf. (дата обращения: 12.12.2020)

3. Исаева А. С. Капкаев Ю.Ш. Феномен «бедных рабочих» //Вестник Челябинского государственного университета. Экономические науки. Выпуск 59.-2017.- С.45-52

4. Мукомель В., Денисенко М. Трудовая миграция во время коронакризиса.- https://econs.online/articles/ ekonomika/trudovaya-migratsiya-vo-vremya-koronakrizisa (дата обращения: 15.11.2020)

5. Синицын А., НакоряковаЛ.И. др. Пульс экономики: основные выводы ежеквартального аналитического бюллетеня Центра стратегических разработок. - https://www.csr.ru/ (дата обращения: 05.11.2020)

6. Система для онлайн-мониторинга российского рынка труда. -https://stats.hh.ru/prof-comparison (дата обращения: 03.12.2020) 
7. Соколов А. Жители России не готовы заместить иностранных мигрантов.- https://www.vedomosti.ru/ society/articles/2020/11/29/848719-zamestit-gastarbaiterov (дата обращения: 05.12.2020)

8. Статистические сведения по миграционной ситуации. Данные МВД. - https://мвд.pф/Deljatelnost/statistics/ migracionnaya (дата обращения: 05.12.2020)

9. Топилин A.В., Парфенцева О.А. Перспективы трудовой миграции в России: от количественных к качественным параметрам Гос. учреждение «Ин-т макроэкономических исслед.» (ГУ ИМЭИ).- Москва: МАКС Пресс, 2008. - 105c.

10. Официальный сайт Федеральной службы государственной статистики. - http://www.gks.ru (дата обращения: 10.11.2020) 